This article is licensed under the Creative Commons Attribution-NonCommercial 4.0 International License (CC BY-NC) (http://www.karger.com/Services/OpenAccessLicense). Usage and distribution for commercial purposes requires written permission.

\title{
Effects of Progressive Additional Lenses on Binocular Vision in Children with Pseudophakia
}

\author{
Minatsu Tanaka Fumiko Matsumoto Shunji Kusaka \\ Department of Ophthalmology, Kindai University Faculty of Medicine, \\ Osakasayama City, Japan
}

\section{Keywords}

Pediatric cataract · Unilateral pseudophakia · Binocular vision

\begin{abstract}
Binocular vision may be compromised in children after unilateral cataract surgery because the distances at which clear vision is present are different for the two eyes. We believe that wearing progressive additional lenses can be effective in improving the binocular vision in children with pseudophakia.

(C) 2018 The Author(s)

Published by S. Karger AG, Basel
\end{abstract}

\section{Introduction}

Binocular vision may be compromised in children with unilateral pseudophakia because of the differences in the distances at which clear vision is present for the two eyes. We treated 4 such cases and found that wearing a progressive additional lens before the pseudophakic eye was effective in restoring and improving stereopsis. 


\section{Case Reports in Ophthalmology}

\section{Case Description}

The clinical characteristics of all cases are summarized in Table 1. We tested stereoacuity of all cases at the same place, using the same TNO test materials, with full correction, and under the same contrast and luminance.

\section{Case 1}

A 6-year-old boy was referred to our hospital for surgical treatment of a cataract in his left eye. His decimal best-corrected visual acuity (BCVA) was 1.2 OD and 0.4 OS. Slit-lamp biomicroscopy showed a developmental cataract, and cataract surgery was performed with lens aspiration and implantation of a toric intraocular lens (IOL). The higher-order aberration $(6 \mathrm{~mm})$, measured with a wave front analyzer (KR-1W; Topcon, Tokyo, Japan) improved from 2.884 root mean square preoperatively to 0.202 root mean square postoperatively (Fig. 1).

Six weeks after the surgery, the BCVA was 1.5 OD and 0.9 OS with an IOL. The near BCVA was $1.0 \mathrm{OD}$ and $0.1 \mathrm{OS}$ with an IOL, 0.9 OS with $+3.50+0.25$ axis $170^{\circ}$ through the IOL. The amplitude of accommodation was $7.75 \mathrm{D}$ for the right eye and $0.58 \mathrm{D}$ for the left eye. TNO test for stereoscopic vision showed that the stereoacuity was 1,980 seconds of arc without correction and 240 seconds of arc with the best refractive correction. Cover test with the best correction showed no shift. We prescribed glasses with a progressive additional lens with $3.00 \mathrm{D}$ addition for the left eye. We selected a progressive additional lens to continuously provide them a suitable visual stimulus (visual acuity at any distance and binocular vision) on a daily basis. Fifteen weeks after the surgery, the BCVA was $2.0 \mathrm{OD}$ and $1.0 \mathrm{OS}$ with +0.25 axis $80^{\circ}$ through the IOL. The near BCVA was $1.0 \mathrm{OD}$ and $1.0 \mathrm{OS}$ with the IOL and progressive additional lens. TNO test with the progressive additional lens improved to 120 seconds of arc.

\section{Case 2}

A 6-year-old boy was referred to our hospital for surgical treatment of a cataract in his right eye. His decimal BCVA was 0.2 OD and 1.2 OS. Slit-lamp biomicroscopy showed an atopic cataract, and cataract surgery was performed with lens aspiration and implantation of an IOL.

One year and 10 months after the surgery, the BCVA was 1.5 OD with $+0.25 \mathrm{D}-0.50 \mathrm{D}$ axis $5^{\circ}$ through the IOL and $1.5 \mathrm{OS}$. The near BCVA was $0.1 \mathrm{OD}$ with full correction at distance through the IOL, 0.9 OD with $+2.50-0.50$ axis $5^{\circ}$ through the IOL, and $1.0 \mathrm{OS}$. TNO test showed that the stereoacuity was 240 seconds of arc without correction and 120 seconds of arc with the best refractive correction. Cover test with the best correction showed no shift. We prescribed glasses with a progressive additional lens with 3.00 D addition for the right eye. Three years and 11 months after the surgery, the BCVA was 1.5 OD with the IOL and progressive additional lens and 1.5 OS. The near BCVA was 1.0 OD with the IOL and progressive additional lens and 1.0 OS. TNO test with the progressive additional lens improved to 60 seconds of arc.

Case 3

A 6-year-old girl was referred to our hospital for surgical treatment of a cataract in her left eye. Her decimal BCVA was $1.2 \mathrm{OD}$ and 0.3 OS. Slit-lamp biomicroscopy showed a traumatic cataract, and cataract surgery was performed with lens aspiration and implantation of an IOL. 
Case Reports in
Ophthalmology

Case Rep Ophthalmol 2018;9:304-309

DOI: $10.1159 / 000488847$

(c) 2018 The Author(s). Published by S. Karger AG, Basel www.karger.com/cop

Tanaka et al.: Effects of Progressive Additional Lenses on Binocular Vision in Children with Pseudophakia

Six weeks after the surgery, the BCVA was 1.5 OD and 1.2 OS with full correction of $+0.25 \mathrm{D}$ $+0.75 \mathrm{D}$ axis $90^{\circ}$ through the IOL, and the near BCVA was $1.0 \mathrm{OD}$ and 0.08 OS with an IOL, 0.8 OS with full correction of $+3.00+0.75$ axis $90^{\circ}$ through the IOL. TNO test showed that the stereoacuity was 1,980 seconds of arc, L-suppression without correction, and 1,980 seconds of arc, sometimes L-suppression with the best refractive correction. Suppression was detected with the plate IV of the TNO test. Cover test with the best correction showed no shift. We prescribed glasses with a progressive additional lens with 3.00 D addition for the left eye. Five months after the surgery, the BCVA was 1.2 OD and 1.0 OS with $+0.50+0.75$ axis $90^{\circ}$ through the IOL. The near BCVA was 1.0 OD and 1.0 OS with the IOL and progressive additional lens. TNO test with the progressive additional lens had improved to 120 seconds of arc.

\section{Case 4}

An 11-year-old boy was referred to our clinic with developmental cataract in the left eye. He had undergone cataract surgery in his right eye when he was 7 years old.

He underwent lens aspiration and an implantation of a toric IOL at our clinic. Before the surgery on the left eye, the BCVA was 1.5 OD with the IOL and 0.6 OS.

One year and 4 months after the surgery on the left eye, it appeared that he had only monocular vision with the glasses that had been prescribed by the referral clinic (Table 2). TNO test with his prescribed glasses was 0 because of R-suppression, while that with the best correction was still 0 without suppression. Suppression was detected with the plate IV of the TNO test. Cover test with the best refractive correction showed that he had an exophoria of several prism diopters. We prescribed glasses with progressive additional lenses for both eyes. One year and 8 months after the surgery, the TNO stereoacuity with the progressive additional lenses had improved to 480 seconds of arc. Two years after the surgery, the BCVA was 1.5 OD with the IOL and progressive additional lens and 1.5 OS with the IOL and progressive additional lens. The near BCVA was 1.0 OD with the IOL and progressive additional lens and 1.0 OS with the IOL and progressive additional lens. The TNO stereoacuity with the progressive additional lenses improved to 120 seconds of arc.

\section{Discussion}

The age of the patients at the time of the cataract surgery ranged from 6 to 11 years. Although the duration of cataracts was uncertain, we believe that their visual functions were normal before the development of the cataract because the visual acuity after surgery was 1.0 or better in all cases. All had good visual acuity at distance and near with the best correction; however, in 3 cases, the binocular vision was poor at near even with the best correction. This was probably caused by the absence of accommodation in the affected eye.

To overcome this, we prescribed spectacles with a progressive additional lens for the pseudophakic eye and a monofocal lens for the fellow eye. This combination led to an improvement of stereopsis in all cases. Even Case 4 who had worn monovision lenses had an improvement in the stereoacuity by wearing the progressive additional lenses at the age of 12 years. Even at an age when the critical period for stereoacuity had passed [1], the presence of differences in the locations of clear vision between the two eyes and wearing monovision lenses could have been the cause of the poor stereoacuity. 
The effects of implanted multifocal IOL in children have been reported. Jose et al. [2] reported that the postoperative stereoacuity ranged from 120 to 1,980 seconds of arc in children with unilateral multifocal IOL. Philipp et al. [3] reported that the postoperative stereoacuity was significantly better in the multifocal IOL group than in the monofocal IOL group after traumatic cataract surgery in children. Based on their reports and the results of our cases, we believe that refractive corrections that make the vision both at distance and near for the pseudophakic eye comparable to that of the fellow eye can contribute to maintain or improve binocular vision in children.

We prescribed the progressive power lens with short progressive zone length considering the sizes of the face and glasses of the children. Although we should primarily select types of lens according to the application, it was inevitable to select the lens physically: we selected lenses with short progressive zone length because glass frames for children were small. Lenses with a progressive zone length of $11-12 \mathrm{~mm}$ were used in this study. It is also required to improvise: we adjusted the wearing position of the glasses to be set with the eye point higher than that for the elderly for easier use of the glass area for near distance. Sometimes, children under 5 years of age might be prescribed bifocal lenses because the progressive zone length of the progressive additional lens cannot fit into small frames.

We believe that progressive additional lens glasses should be considered for all children with unilateral pseudophakia to obtain better binocular vision. However, additional studies are needed with a larger number of patients.

In conclusion, wearing a progressive additional lens is effective in establishing and improving binocular vision in children with unilateral pseudophakia.

\section{Statement of Ethics}

This study followed the tenets of the Declaration of Helsinki for research involving human subjects and was approved by the Ethics Committee of Kindai University Faculty of Medicine (No. 28-264). Informed consent was obtained from all the patients.

\section{Disclosure Statement}

All authors read the manuscript and agreed to its publication in this form. The manuscript is not under simultaneous consideration by any other publication. The authors have no conflicts of interest to declare.

\section{References}

1 Fawcett SL, Wang YZ, Birch EE. The critical period for susceptibility of human stereopsis. Invest Ophthalmol Vis Sci. 2005 Feb;46(2):521-5.

2 Cristóbal JA, Remón L, Del Buey MÁ, Montés-Micó R. Multifocal intraocular lenses for unilateral cataract in children. J Cataract Refract Surg. 2010 Dec;36(12):2035-40.

3 Jacobi PC, Dietlein TS, Konen W. Multifocal intraocular lens implantation in pediatric cataract surgery. Ophthalmology. 2001 Aug;108(8):1375-80. 


\section{Case Reports in \\ Ophthalmology}

Case Rep Ophthalmol 2018;9:304-309

DOI: $10.1159 / 000488847$

(c) 2018 The Author(s). Published by S. Karger AG, Basel www.karger.com/cop

Tanaka et al.: Effects of Progressive Additional Lenses on Binocular Vision in Children with Pseudophakia

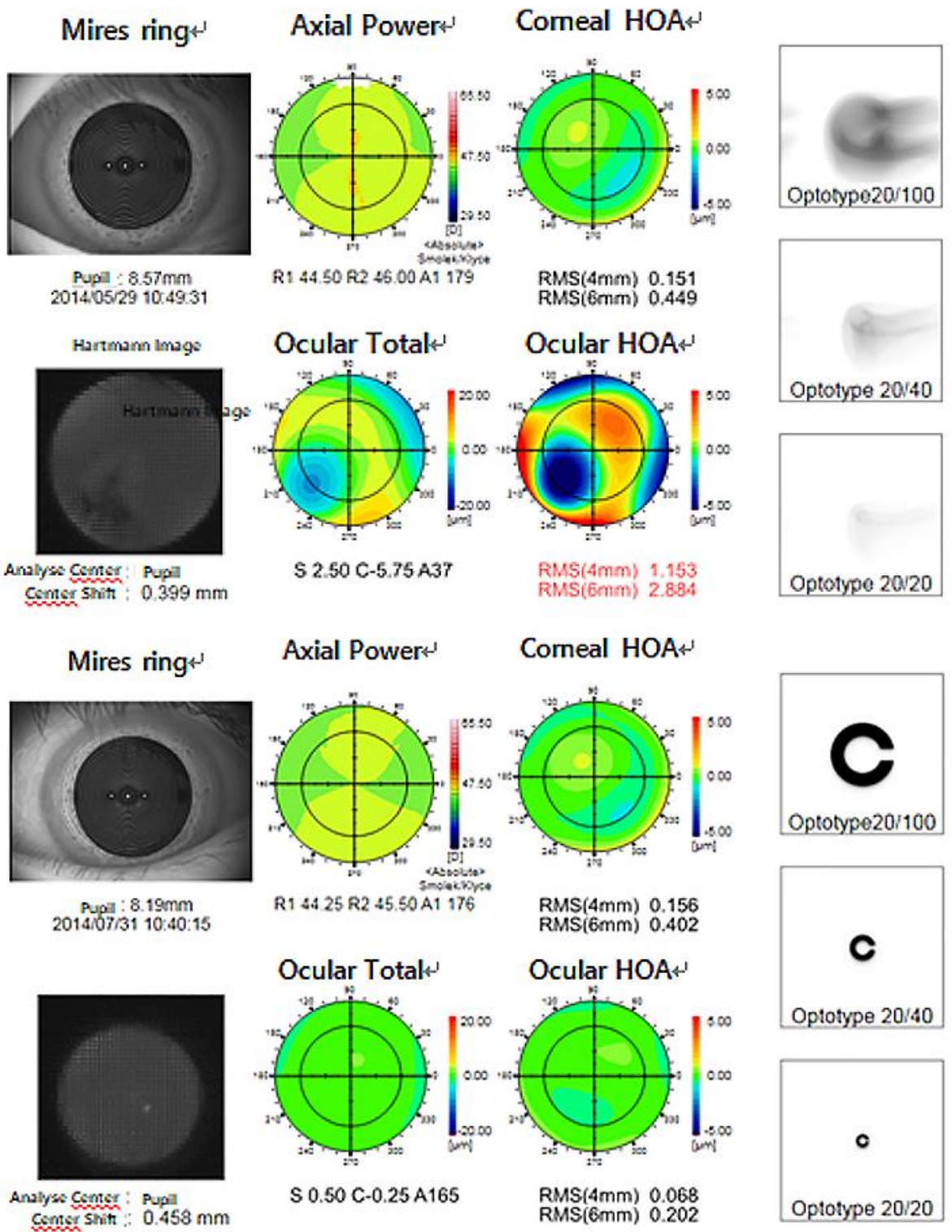

Fig. 1. Wave front analysis of Case 1. Preoperative higher-order aberration (6 mm) was 2.884 root mean square (RMS), which was reduced postoperatively to 0.202 RMS. 
Tanaka et al.: Effects of Progressive Additional Lenses on Binocular Vision in Children with Pseudophakia

Table 1. Summary of cases

\begin{tabular}{|c|c|c|c|c|c|c|c|c|c|c|c|c|}
\hline \multirow[t]{3}{*}{ Case } & \multirow{3}{*}{$\begin{array}{l}\text { Age, } \\
\text { years/ } \\
\text { Sex }\end{array}$} & \multirow[t]{3}{*}{$\begin{array}{l}\text { OD/ } \\
\text { OS }\end{array}$} & \multirow[t]{3}{*}{$\begin{array}{l}\text { Cause of } \\
\text { cataract }\end{array}$} & \multicolumn{3}{|c|}{ Refractive error } & \multicolumn{3}{|l|}{ BCVA } & \multicolumn{2}{|c|}{$\begin{array}{l}\text { Stereoacuity, } \\
\text { seconds of arc }\end{array}$} & \multirow{3}{*}{$\begin{array}{l}\text { Period o } \\
\text { wearing } \\
\text { PPL, } \\
\text { months }\end{array}$} \\
\hline & & & & \multicolumn{2}{|l|}{ cataract eye } & \multirow{2}{*}{$\begin{array}{l}\text { fellow } \\
\text { eye }\end{array}$} & \multicolumn{2}{|c|}{ cataract eye } & \multirow{2}{*}{$\begin{array}{l}\text { fellow } \\
\text { eye }\end{array}$} & \multirow{2}{*}{$\begin{array}{l}\text { pre- } \\
\text { PPL }\end{array}$} & \multirow{2}{*}{$\begin{array}{l}\text { post- } \\
\text { PPL }\end{array}$} & \\
\hline & & & & $\begin{array}{l}\text { pre- } \\
\text { operation }\end{array}$ & $\begin{array}{l}\text { post-operation } \\
\text { (with IOL) }\end{array}$ & & $\begin{array}{l}\text { pre- } \\
\text { operation }\end{array}$ & $\begin{array}{l}\text { post-operation } \\
\text { (with IOL) }\end{array}$ & & & & \\
\hline 1 & $6 / \mathrm{M}$ & OS & $\begin{array}{l}\text { developmental } \\
\text { cataract }\end{array}$ & $+0.50-3.00$ & +0.25 & +0.75 & 0.4 & 1.0 & 1.2 & 240 & 120 & 2 \\
\hline 2 & $6 / \mathrm{M}$ & OD & atopic cataract & $-0.50-1.50$ & $+0.25-0.50$ & n.c. & 0.2 & 1.5 & 1.2 & 120 & 60 & 24 \\
\hline 3 & $6 / F$ & OS & $\begin{array}{l}\text { traumatic } \\
\text { cataract }\end{array}$ & $+0.50+1.00$ & $+0.25+0.75$ & +0.25 & 0.3 & 1.2 & 1.2 & 1,980 & 120 & 3 \\
\hline 4 & $11 / \mathrm{M}$ & os & $\begin{array}{l}\text { developmental } \\
\text { cataract }\end{array}$ & $+2.75-3.50$ & $-0.50-1.75$ & $\begin{array}{l}+1.75 \\
-3.00\end{array}$ & 0.6 & 1.5 & 1.5 & Nil & 120 & 8 \\
\hline
\end{tabular}

PPL, progressive power lens; pre-PPL, before wearing progressive power lens; post-PPL, after wearing progressive power lens; n.c., non corrigunt.

Table 2. Prescribed spectacle power aimed for monovision and visual acuity of Case 4 (bilateral pseudophakia)

\begin{tabular}{llllll}
\hline OD/OS & & $\begin{array}{l}\text { Visual } \\
\text { acuity }\end{array}$ & $\begin{array}{l}\text { Spectacle } \\
\text { power }\end{array}$ & BCVA & $\begin{array}{l}\text { Refractive } \\
\text { error }\end{array}$ \\
\hline OD & distant & 1.0 & $+1.25-2.50$ & 1.5 & $+0.50-2.00$ \\
& near & 0.2 & & 1.0 & $+2.75-2.00$ \\
OS & distant & 0.2 & $+3.75-2.50$ & 1.5 & $-0.50-1.75$ \\
& near & 0.5 & & 1.0 & $+1.75-1.75$ \\
\hline
\end{tabular}

